industry as a whole; he looks at his balance sheet and there may be a loss to him.

Such manufacturers will only take women applicants when there are no suitable male applicants. Fortunately for professional women, that condition has already been reached in many branches of British industry. Women will be accepted because there is no other choice. Women should think carefully, however, before deciding on particular careers in industry. In such careers as general management, personnel management, and industrial medicine, a break for marriage and child-bearing should be no handicap and should enable the middleaged women to return to industry even moro fitted for her job. In rapidly evolving specialist fields, however, where knowledge of chemistry, physics and other natural sciences are involved, she may find it easy to secure a post before marriage but difficult to return to it afterwards.

Women who wish to find employment in industry may find this report disappointing; they should be consoled by the knowledge that industry can no longer do without them.

\section{EARLY HISTORY OF THE SAUROPSID REPTILES}

TN palæontology, as in other branches of science, small things often lead to great and far-reaching results. It is not unexpected, therefore, that Prof. D. M. S. Watson, with his usual searching eye and his vast knowledge of reptilian structure, should develop some significant conclusions from his study of eight small reptilian skulls and associated skeletal materials, contained in a nodule of rock from the Cisticephalus zone of the Karroo series of South Africa. These fossil remains, representing the genus Millerosaurus, are described in detail in a recent paper* by Prof. Watson in which he turns to a discussion of the basic classification and the relationships of all the reptiles.

Millerosaurus, as Watson shows, is a small fossil reptile with a long body and slender limbs. The skull is basically cotylosaurian, but it has a welldeveloped lateral temporal fenestra, situated beneath the post-orbital and squamosal bones. A part of the skull roof is covered with bony osteoderms fused to the underlying skull bones, and at the back of the skull the quadrate is characterized by a long ascending process rising to the supratemporal bone. In the area behind these bones is a small stapes, quite comparable to the stapes of a lizard, which in life must have formed a communication between a large tympanic membrane and the fenestra ovalis. The pectoral girdle has a 'screw-shaped' glenoid, and in the hind foot the fifth digit is complete and divergent. The fifth metatarsal is straight-not a hook-shaped bone. Such are a few of the bare facts concerning the osteology of Millerosaurus. What are the implications?

In 1916 Goodrich saw a basic dichotomy within all but the most primitive reptiles, the two branches of which he designated the Sauropsida and the Theropsida. Watson upholds this view of reptilian evolution, and he places Millerosaurus and its rela. tives as very important ancestors of sauropsids. In

* Phil. Trans. Roy. Soc, B, No. 673, 240, 325 (1957): On Miller osaurus and the tarly History of the Sauropsid Reptiles. By Prof line with previous work, he believes the ear region to be of particular diagnostic value in the determination of sauropsid and theropsid relationships. Thus Millerosaurus is an ancestral sauropsid, in part because it has the type of ear structure briefly described above. (In the theropsids, according to Watson, the tympanic membrane was lost for some time during late Palæozoic times, and in later forms was re-established as a neomorphic structure, not homologous with the tympanic membrane of the sauropsids. This part of his thesis is disputed by some authorities, notably Vaughan in a recent contribution.)

Because of the important situation of the millerosaurs (as Millerosaurus and its near relatives may be designated) in time and in their taxonomic position, this study throws light on many other reptiles and on the whole subject of reptilian classification. Watson believes that the temporal fenestræ are of secondary importance in determining reptilian relationships. He suggests that the millerosaurs, which are essentially cotylosaurs with lateral temporal fenestræ, might well have been ancestral to the prolacertilian reptiles, to the eosuchians and to the great thecodontarchosaur complex; in short, to sauropsids, which comprise the great majority of reptiles through time. $\mathrm{He}$ believes that the evolution of the diadectids may represent an entirely separate reptilian development, parallel to the rise of the procolophonid-millerosaur stem, the true base for the sauropsids.

Watson's conclusions are of broad consequence to students of reptilian evolution, and the accumulating mass of evidence would seem to reinforce these ideas. Since the concept of an early dichotomy of evolving reptiles is of such significance to future work in this field it is perhaps unfortunate that Goodrich's term 'Theropsida' is being continued. This word might well be abandoned in favour of some other name that is less apt to get confused in many minds, and particularly in many typewriters and printing pressez, with the long-established taxonomic designation 'Therapsida'. Indeed, though not so serious a case, the term Sauropsida bears too strong a resemblance to Sauropoda for complete comfort. Could we not have two new names for the two primary lines of reptilian evolution? EDWIN H. CoIBERT

\section{FILTER FEEDING IN FLAMINGOES}

GILTER foeding is very rare among the higher vertebrates-among the mammals it occurs only in the whalebone whales, and among the birds in the Anatidae and in some species of a few other families. It reaches its highest development in the flamingoes, in which it has been investigated by Miss Penelope M. Jenkin, who reports her results in a recent memoir*.

There are six species of flamingo according to some authorities, or four, one of which is divided into three sub-species, according to others; they are partitioned between three genera. Flamingoes are widely dis. tributed throughout the warmer regions of both old and New Worlds, and their distribution is determined by the situation of the salt or alkaline lakes where their food occurs in abundance. They thus congregate near the great deserts of the world, often at high altitudes. When Miss Jenkin was working on the

- Phil. Trans. Roy. Soc., B, No. 674, 240, 401 (1957): The Filter Feeding and Food of Flamingoes (Phoenicopteri). By Penelope MI Jenkin. (London, Royal Society, 1957.) 35s. $6 d$. 